Kay ${ }^{1}$, V.F. Hillier', A.L. Rector ${ }^{1}$, C.J. Taylor ${ }^{2}$

7.Medical Informatics Group, Department of Computer Science and 2. Diagnostic and Investigative Sciences, Medical School, University of Manchester, UK.

\title{
Education and Training
}

\section{Medical Informatics Education at the University of Manchester}

\begin{abstract}
Manchester University offered the first full time, undergraduate Medical Informatics degree programme in the UK. The B.Sc. in Medical Informatics was conceived in 1992 and its first cohort of students, taking the three year version, graduated in 1996; those students taking the four year version of the undergraduate degree will graduate in July 1997. The paper describes our somewhat turbulent experience of the first four years, highlighting both the difficulties and successes of launching an inter-disciplinary degree. First, the story of the programme's development is given by way of an introduction and to establish a suitable context for describing the programme in more detail. Then, after presenting the aim and objectives of the programme, we describe the overall structure of the course, and reflect upon certain key issues for establishing Medical Informatics as a distinct, academic discipline.
\end{abstract}

Keywords: Medical Informatics, Undergraduate, B.Sc., Awareness.

\section{Introduction}

The Medical Informatics Board came into being because it was recognised that the University of Manchester had four different research groups operating successfully in Medicallnformatics. Its establishment within the University was seen as an attempt todevelop synergy between the groups and to bring more cohesion to their endeavours. One aspect of its work was to establish a degree course which would complement the research work; an undergraduate B.Sc. involving cross faculty partnership.

The Manchester B.Sc. was established on the belief that Medical Informatics is rapidly emerging as a distinct discipline requiring a unique blend of education in bio-medical science, informatics, and management science. As the University of Manchester was already recognised internatonally as providing excellent educa-

tion and research in these particular component disciplines, it seemed to be ideally placed to invest in a new degree programme; one which would provide a showcase for its strengths, whilst attracting good quality applicants. A relatively small number of good quality candidates on a new programme was an attractive proposition, as the UK government was at that time encouraging all universities to expand despite the minimal amount of resources available for such an expansion.

Once the outline case for the degree had been accepted by the University, it was required to detail the Medical Informatics curriculum. Given the resource constraints and the initial interest of the Department of Computer Science, the Faculty of Medicine, and the Health Services Management Unit, it was not surprising that the flavour of Medical Informatics curriculum at Manchester would comprise elements from the constituent founders [1]. It was necessary, however, to appoint a Director and Board of studies, to determine the underlying philosophy, to define the structure of the programme, and to agree on the relative contributions from each partner. Once agreed, it was then necessary to satisfy the internal quality standards before finally publicising the degree to the outside world.

\subsection{Product, Risk and Responsibilities}

The curriculum is necessarily multidisciplinary and brings together three inter-related aspects of Medical Informatics within the same programme of study. Manchester is aware, however, that an undergraduate programme in Medical Informatics must be a synthesised, coherent and marketable product which nethertheless has to be developed and delivered in the existing University setting 
[2]. As a new undergraduate programme, it was recognised that it would be likely to run at a loss for at least the first cycle (i.e. 4 years), and most probably the second too. As the first degree of its kind in the UK, the success of the Medical Informatics venture was particularly difficult to forecast, and therefore it was regarded as being a relatively 'high risk' undertaking. The programme that subsequently developed reflected the projected level of involvement by the partners, giving equal weight to the Faculty of Medicine, and the Faculty of Science and Engineering (40\%), and the remainder to the management component (20\%). There was incentive for all three partners to attract a reasonable number of high quality students, as none could initiate and sanction a new degree programme lightly.

\subsection{Launching the Degree}

Once approved by the teaching standards committee of the University, the programme was launched; the intention being to attract suitable candidates for 1993. Considerable publicity was required to attract students through direct entry for the first few years, rather than by the normal application route; the official UK information about courses being offered to schools has a two year lead time. The formal entry qualifications were set to attract school leavers (i.e. 18 year olds), although 'mature' student entry was encouraged. We succeeded in attracting 14 students by direct marketing methods and the -Medical Informatics course(s) did indeed begin in September 1993, offering a blend of education in biomedical, information and management sciences, underpinned by a knowledge of human pathobiology. The reason for the plural designation for the course is that we offer a three years B.Sc. (with Honours), and a four year B.Sc. (with Honours), M.Inf. The distinction will be addressed later.

\section{Aim and Objectives}

In establishing these courses, we are arguing forMedical Informatics as essentially a distinct academic discipline. Visionaries such as Haux and Leven $[3,4]$ have argued for this and we would give our support to this aim. But whereas others have had a long history in this endeavour, most notably in Germany for over twenty years [5] and Canada for over ten [6], the UK have had limited success in establishing Medical Informatics programmes in a University setting. In 1993, the Manchester degree was the first undergraduate full-time degree in the UK, although several M.Sc. and diploma courses pre-dated its launch.

The Manchester degree was first mentioned in a journal article publishing course criteria set by the IMIA working group 1 on education [7]. It can be classified as an 'A type' according to that criteria, i.e. it comprises the following three attributes:

- A dedicated curriculum in Medical Informatics

- The entire academic program is at least equivalent to two years of full time study; (in fact it is at least three years.)

- Medical Informatics forms part of the degree, diploma, or certificate designation.

Our two primary objectives related to the degree are concerned primarily with the means to achieve academic recognition and, secondly, to make a contribution to the understanding of what Medical Informatics is by fostering an appreciation of what it can do within the domain of healthcare [8].

\subsection{What Medical Informatics is: \\ A Holistic Subject}

We believe that it is not desirable to teach individual constituent parts of the subject in complete isolation to the others and then to expect the student to acquire an appreciation of the richness of Medical Informatics. To do so, would impoverish what we would consider to be a holistic subject. We believe there to be a clear distinction between Medical Informatics and 'Informatics for medics'; the latter being a relatively small subset of the whole discipline. We would argue that it is not sufficient either, for Medical Informatics to be regarded simply as a brief Computer Science conversion course which postgraduates from clinical disciplines can take, or vice versa.

The course therefore aims to produce a new creature; a unique type of graduate with sufficient knowledge to function effectively in a new role within the increasingly complex healthcare environment. The Medical Informaticians of today acquired their knowledge and skills by a process of osmosis over a considerable period of time, in a relatively ad hoc and unstructured way. The need now is such that we should be attempting to do better through a coherent programme of Medical Informatics education combining theoretical and practical experience within the domain of healthcare. It is not an attempt to denigrate experience, rather the objective is to provide a firm foundation on which experience can build.

\subsection{Towards Recognition of What it Can Do}

Neither is the reason for emphasisin a coherent approach to belittle existing programmes of study. Rather it reflects the growing recognition that there are strong vocational elements to the new discipline [9]. These elements require would-be Medical Informaticians to be immersed within the health-care situation so as to become acclimatised and sensitised to the need: and demands of health-care and its culture. This is necessary from a peda gogical perspective. It is also impor tant that the other health-care professionals become aware of our students activities and come to appreciate the 
role of this fledgling discipline. It follows that we have a high expectation of the student, that their projects and placements are to be credible and worthy so as to earn respect. The academic components related to the medical knowledge subjects, therefore, are important, not least because they will facilitate a shared understanding and mutual intelligibility between the various actors within the healthcare domain. Such understanding may help to avoid today's often ineffective communication between clinical and technical staff which can often result in systems, analyses and results of dubiousquality. If it is ever to be recognised as a profession, then the contribution of Medical Informatics to the healthcare domain must be made explicit[10].

\section{The Organisation of the B.Sc. at Manchester}

\subsection{Rationale and Organisation of the Three Year and Four Year Degrees}

Two undergraduate courses are offered at Manchester; a three year B.Sc. Medical Informatics and a four year BSc/M.Inf Medical Informatics. The student can elect to do either version at their initial registration at the University. Their decision is based upon theirfunding possibilities, and/or their study requirements. The rationale for introducing such flexibility into the organisation of the degree was for bothacademic and marketing purposes: the former had to with defining the scope and boundaries of a broad discipline, and the latter as a means of attracting students at a time of uncertain funding opportunities for entry to highereducation.

The provision of a three year version of the course explicitly recognised that for many courses in the UK, three years of study is the norm. For students registered for the four year course, the flexibility of changing to the shorter version meant that they can react to any change in their particular circumstances. The fourth year course, however, is considered to be the more desirable option as it comprises an extended placement in a health-care organisation or research setting, in addition to a wider selection of taught academic subjects. The fourth year, therefore, is seen as giving the student a better introduction to the healthcare domain, and as a means to encourage the more able student to progress to research. Furthermore, the four year course is compatible with the general European practice, which from a marketing perspective should have made the course more attractive to EEC students outside of the UK.

The student is awarded a B.Sc., M.Inf on successful completion of the fourth year. This award is not a postgraduate degree; it is recognition that the student has studied a broader based undergraduate degree with more experience, both practical and theoretical, than is possible in the three year version. The distinction is also a temporal anomaly. In our opinion, students who have been studying Medical Informatics full time for three years are on a par with those who take a one year conversion M.Sc.. In time, we see the need to revise and improve the standard of the post graduate award, to offer a specialist M.Sc. in Medical Informatics.

Academically, the first three years of both versions of the course are the same, identical in structure and content. The third year is either the final year for the student enrolled on the three year course, or the foundation for a fourth year which begins with a full first semester placement. Those registered for the four year course, however, have to reach a required level of academic achievement to be allowed to continue. These students still have the choice of completing in year three if they feel it is to their advantage to do so. This flexibility permits one student to leave for an employment opportunity whilst permitting another student to gain more practical experience before seeking employment so avoiding, we hope, the general 'catch 22' problem which often frustrates new graduates. As the fourth year also offers further topics within Medical Informatics and broadens their exposure to the subject, students are encouraged to opt for the four year version when they initially register.

Students are registered with the Department of Computer Science in the Faculty of Science. At the start of the programme, the administration, further development, and delivery of the programmes was shared amongst the three partners. At the beginning of the third year, however, the Health Services Management Unit found that they had to withdraw from their part of the course. The remaining partners then had to re-organise and to compensate the curriculum by buying in those modules which had already been offered to the students.

All academic courses are naturally subject to revision and evolution. The sudden withdrawal of the management unit, however, led to an immediate academic re-appraisal both of the way material was delivered and the effectiveness of the managerial component. The overall flavour of the course, however, has been unaffected by the re-arrangement, although some extensive 'furniture moving' was required to accommodate the changes. Discussion of the actual changes is left until section 4.4.

\subsection{Course Structure}

The University has recently moved to a two semester structure for the academic year and embraces a modular scheme, with each module having a credit value. For the Medical Informatics degree each semester comprises the equivalent of six mod- 
ules. Each module in the first two years comprises 40 hours taught contact time, and is expected to have a similar time spent by the student in private study. For the first two years, all students follow a common core curriculum, supported and reinforced by practical work in the form of case studies, group-work, and individual projects and laboratory exercises. In years three and year four, taught contact time reduces to 24 hours per module, but the student is expected to do more self study and to concentrate on project/placement work. In the latter years, students opt to specialise in one of the three component disciplines, or themes, doing project work (equivalent of three modules) or their placement (equivalent of six modules) respectively instead of taught modules.

In keeping with the University's normal practice, modules may be assessed either by examination only, in January (first semester modules) or June (second semester modules); by continuous assessment only; or, more commonly, a combination of discrete examination and continuous assessment. Students are required to achieve an overall pass in order to be able to proceed from the first to the second year. At the beginning of the second semester in the third year, those who are registered for the four years and who have achieved sufficiently good assessment results may opt for the four year programme. Joint examiners meetings are held to check for consistency across the themes of the course. For specific details of the types of modules that are offered in each theme, the reader is referred to 'Medical Informatics at Manchester: Science and Story' in the report of the EDUCTRA initiative [11,12]. Projects and placements are assessed in part by the organisation offering the work, but the over-riding responsibility for the assessment is by the academic department which requires and expects at least a dissertation, and, if appropriate, a demonstration of software.

\section{Certain Observations from our Experience}

As we reach the end of the first entry cycle, this paper provides an ideal opportunity to reflect upon our experience. In keeping with the spirit of [13], we see value in recording the problems encountered as well as the successes.

\subsection{Teaching by Numbers}

It was a given position that the degree could be offered in 1993 with minimal resource being expended. However, the delivery cost of providing a new, multi-disciplinary, undergraduate degree across several Faculties and of operating a new type of degree within existing departmental

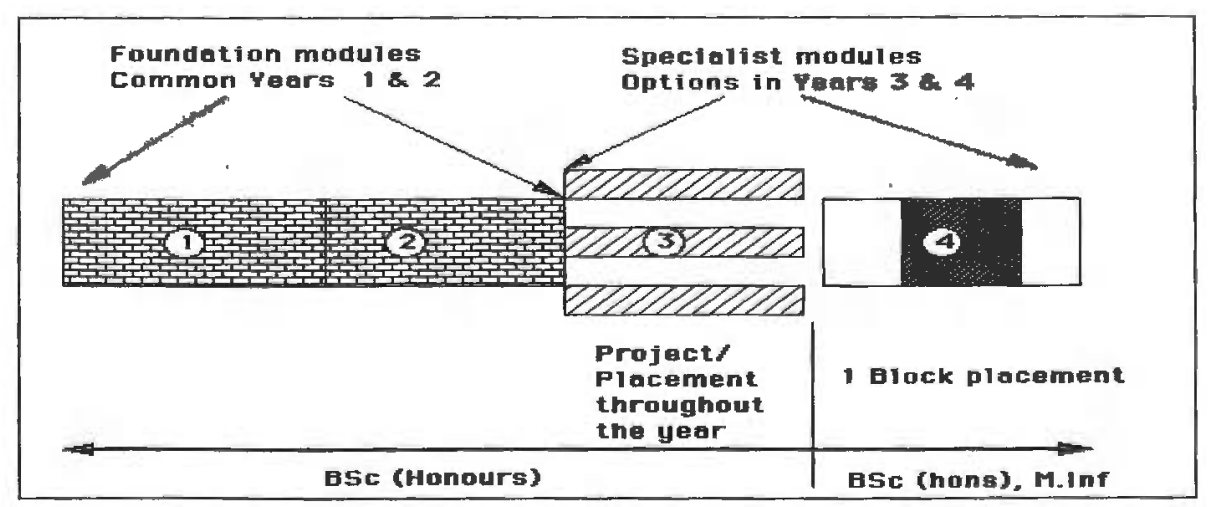

Fig 1: Structure of Course showing the practical specialisation in years three and four. structures had been underestimated. In part this was due to unforeseeable external factors such as government policy shifts, changes to higher education organisation, and recruitment mechanisms. Internal factors such as traditional university cost models which favour single source rather than multidisciplinary courses, were poorly understood, and the high administration and academic overheads associated with communication and service to students across departments had not been fully appreciated.

The novelty of the degree in the UK setting, meant that there was considerable uncertainty with respect to potential number of applicants for the degree. It was considered from the outset, therefore, to be a 'risk' which committed the University to providing a four year course even if only one student applied and was accepted. We had estimated that after the first full cycle the degree would attract thirty to forty students per annum, and had seemed to be on track when we began with 14 . The next year, 15 were accepted which was below the expected number of 20. Alarm bells rang when the third intake dropped to 7 .

The higher than expected overheads, made worse by a poor level of recruitment, had serious implications for a programme which had been launched on the understanding that there was to be minimal resource available. The original proposal had considered the long term view, i.e. the claim that the degree would be viable only after the second cycle. In the short term, however, recruitment numbers effectively determine resource, and consequently this had an impact on staffing levels and loading, as well as making it difficult to be pro-active in marketing the degree.

\subsection{Selling Medical Informatics by the Pound}

Resource to one side, there was (is) 
still the need to market Medical Informatics effectively. For higher ducation in the UK, it means presenting the emerging discipline to those who influence potential students in terms to which they could relate. As enthusiasts and activists in the field, we had not appreciated how difficult it was for 'outsiders' to buy into the value and discipline of Medical Informatics. We used words and jargon which did not communicate.

Soundings outside the University, both at home and abroad, suggested that Medical Informatics was becoming increasingly important and that any graduate from such a programme would be well sought after, not only by research groups and academia, but also by industry, i.e. suppliers of information and communication technologies to healthcare, by purchaser and provider organisations of healthcare and byconsulting companies. In short, there was a market for our potential graduates which it was presumed, not unreasonably, would attract a reasonable annual intake.

This assumption, that a demand for these graduates ensured a reasonable intake level, was too simplistic. We found that the demand had not made itself known to those who gave career advice to the student looking at a university place. Similarly, parents, still very influential in the decision making process, were reluctant to recommend a subject to their son or daughter which they did not recognise, or believe to be established such as Computer Science or Medicine. A major issue then, has been the relatively low level of awareness of Medical Informatics among not only potential students but their teachers, career advisers and parents. Students, and parents, in particular, can not easily gauge what potential if any exists in Medical Informatics for a future career. School careers officers had no similar UK Medical Informatics courses to compare, and so were un- able to advise. The consideration of the academic discipline of Medical Informatics as a product to be marketed and sold raises the difficult questions of definition, description and, perhaps, of ownership.

\subsection{The Spirit of Medical Informatics}

There are many definitions, descriptions, and even names for Medical Informatics, and who is to say which is right? Medical Informatics to some is a catch-all term which encompasses the whole field of healthcare, and incorporates aspects accommodated by the broadest definitions of the information sciences, system sciences, and management $[14,15]$ : If the conference proceedings of the long standing and acknowledged Medical Informatics societies, such as AMIA, EFMI, and IMIA, are browsed it is easy to appreciate the diversity and richness of the discipline and its total inclusivity of subject matter under the banner of Medical Informatics. The proposed guidelines for European curricula for education and training in health informatics [16] begins by suggesting a working definition and then an informal one immediately after. Despite the qualifications applied to these definitions, it is extremely unlikely that the definitions will satisfy many.

In a thoughtful study, Grémy [17] analysed the separate terms which make up the composite term, Medical Informatics. It is possible to conclude from that discussion and that of others $[18,19]$, that the whole concept to which this term refers is greater than the sum of its parts and goes much further than the meaning that each individual component-termmight convey, both linguistically and operationally. To use a 'systems' term, Medical Informatics has emergent properties.

Blois and Shortliffe [20] point out that the term Medical Informatics originated in Europe, representing a concept which subsumes not only com- putation but also those related concepts of data, information, and knowledge as applied within the context of the health-care domain. Perhaps Winograd's and Flores's [21], 'larger goal', i.e. "to clarify the background of understanding in which the discourse about computers and technology takes place, and to grasp its broader implications." is also a valid goal for Medical Informatics?

Consider the following quote:

"the precise definition of this area of study is rendered difficult by the development of a variety of specialisms which include computer science, information technology, information systems engineering, business information systems and Information science. Notonly are these areas of study relatively new compared with the subjects taught in Higher Education institutions, but they are often approached in different ways and are placed in different faculties or schools in different institutions or even the same institution." [22]

It refers not to Medical Informatics as one might expect but to the more recognised and established discipline of Computer Science, which, like the other subjects within higher education in England, had to submit to a national assessment exercise! It may be argued that 'Computer Science' too is a misnomer. As Harel mentions, "terming the field 'computer science' ... is like referring to surgery as 'knife science'." Harel regards Algorithmics as the 'Spirit of Computing' [23]. We need something analogous for Medical Informatics, because we share some of the problems. To quote him again in reference to a strange dichotomy:

"here is a science about which some people know nothing, but about which a rapidly increasing number of people apparently know everything! As it happens, however, the really unusual phenomenon is that large and important parts of the science of computing are not sufficiently known, not only to members of the first 
group, but to members of the second group as well (page 9)."

Medical Informatics can not afford to limit itself to 'bits and bytes', merely to computer literacy if it is to endure [24]. As Coiera remarks, "Medical Informatics is as much about computers as cardiology is about stethoscopes." [25]. So what then the value of the name or the precision and uniqueness of a definition? From our point of view a concise, pithy description of the discipline would have been invaluable both for the peace of mind of our students and particularly for the purposes of marketing. Our students had been bombarded with questions of identity from their peers and from external lecturers as to what Medical Informatics meant from day one. From the literature, the students had also been exposed to the many diverse definitions of their subject. The result was bewilderment. It was decided that as part of a third year course on 'Foundations of Medical Informatics' to set an assessed piece of work on the topic "What is Medical Informatics?". After all, these students were our customers as well as our first intake, they were having the 'furniture' moved around them whilst doing the course, and were also destined to be our first graduates. From their collective work, Kay abstracted a description which is now used in the degree's publicity material:

Medical Informatics is the theory and practice of using information responsibly in the context of healthcare. ${ }^{1}$

As with other descriptions it is possible to find fault with its scope. Like the European curricula guidelines it places the emphasis upon information which is pivotal and can be used to place terms such as 'data' and 'knowledge' into context. It can be argued that as a definition it is not sufficient, but that is to miss the point. Its value is that it is simple; a one-liner which people can remember and quote. It is memorable, therefore, and might go a little way in raising the awareness of people not already familiar with the field.

\subsection{Rock and Role}

The withdrawal of the management partner led to a re-assessment of what we included as being core to the term. The local pragmatics of the situation again, perhaps, played its part and suggested to us that management, albeit still important as a supporting discipline, is not as central to Medical Informatics as we first supposed! Our understanding of the role of the management theme has now changed.

The original academic purpose for including the management theme was primarily to emphasise the organisational context and what might be called the art dimension of the discipline. The Health Services Management Unit's contribution was replaced by a more generic management component offered by the Federal School of Management in Manchester and complemented by selected, individual modules given by contracted-in staff. The generic nature of the replacement, paradoxically strengthened the academic nature of the degree, although it was found necessary to provide additional modules specifically about healthcare organisation to re-enforce the relevance of the material to the students.

Modules such as Organisational behaviour, Organisational Development, Health Policy, and Health Economics are indeed seen as being essential and important parts of the
Manchester degree, but these mod. ules are perhaps more closely related to other subjects such as information systems, psychology, politics and eca nomics as they are to management per se.

\subsection{Other Issues}

The experience with the degree has highlighted a number of other issues, summarised as follows:

Depth versus breadth. In many areas, judgements have to be made about the depth and level to which students should take particular areas, and the trade off between a broad based degree and in depth knowledge

Generalist versus specialist. To whatextent should Medical Information students be offered courses tailored specifically to their needs, and to what extent do they benefit from working alongside medical and/or computer science undergraduates;

Logistics and time tabling. The complexity of managing such a course offered by separate, disparate and geographically scattered department should be recognised. To ensure that staff, and staff-student communicas tions are effective, and that students? expectations of support and pastoral care are met is resource intensive.

\section{Concluding Discussion}

The degree courses at Manchester were fashioned by the interaction of a consensus view of 'the spirit of Medical Informatics' and the local situation. The designers were determined to give high quality educational experience in the different components, but to bring these fields together assumes a common understanding and framewortk which we have not entirely achieved. To speak of 'grand challenges' and

\footnotetext{
${ }^{1}$ It was modified subsequently (as a result of a comment received at the MIE96 presentation IMIA WG 1), substituting 'effectively' 'responsibly', the latter subsuming the former whilst also implying the necessary ethical response.
} 
'quests for the holy grail' in relation to Medical Informatics is to assume we have arrived [26]. Perhaps the greatest challenge is to reach consensus on the framework itself.

However, we have made considerable progress towards our goal. The academic quality of the course has been high, as recognised both by the University's internal working party and by the degree successfully receiving external accreditation from the British Computer Society in 1996 , despite its interdisciplinary status. Students have out performed others on more established courses, publishing project work, and have been awarded external prizes for the quality of their work. Indeed, as predicted, some of the third year project work has been on a par with good M.Sc. post graduate work.

Despite these successes, the selling of the degree and the recruitment of students has not been a success. Whether this is an issue for Medical Informatics or a specific problem with attempting to set up an undergraduate degree programme in the current UK setting is unclear. Ironically, all our indications are that the demand for graduates is strong and growing. The degree course is guaranteed by the University to the year 2000 , and we are actively looking to build on this experience, either by repackaging the material in different forms for a different type of customer, orby broader efforts to increase awareness of Medical Informatics. The lessons learned, and above all the graduates taught, will continue to make contributions to health-care and Medical Informatics beyond the Millennium.

Acknowledgements: We would like to thank Vic Peel of the Health Services Manpgement Unit, and especially Jane Price, Peter Hudson, and John Kelly, for their contributions during the 'furniture moving'.

\section{References}

1. Peel VJ. Management-focused health informatics research and education at the University of Manchester. Meth Inform Med 1994;33:273-7.

2. Kay S, Price J, Hillier VF. The University of Manchester B.Sc./MInf Medical Informatics Degree Programme. In: LloydWilliams M. ed. SHIMR 95. The First International Symposium on Health Information Management Research. The University of Sheffield 1995.

3. Haux R. On medical informatics. Meth Inform Med 1989;28:66-8.

4. Leven FJ. Curriculum for medical informatics at the University of Heidelberg/School of Technology Heilbronn. Meth Inform Med 1994;33:262-7.

5. Haux R, Leven FJ. Twenty years medical informatics education at Heidelberg/ Heilbronn: Evolution of a specialised curriculum for medical informatics. Meth Inform Med 1994;33:285-9.

6. Protti DJ.Health information science at the University of Victoria: The first ten years. Meth Inform Med 1994;33:268-73.

7. Dickhaus H. A comparative summary of six health/medical informatics programs. Meth Inform Med 1994;33:254-7.

8. Kay S, Hillier VF, Holbourn A, Donnan S, Peel V, Rector AL, Taylor CJ. Medical informatics education: a new curriculum for an established concept. In: Barahona P, Veloso M, Bryant J, eds. Proceedings MIE94, Lisbon, 1994:685.

9. Hasman A, SosaM. Education and training of health informatics in Europe. In: Hasman A, Albert A, WainwrightP, KlarR, Sosa M, eds. Education and Training in Health Informatics in Europe. Amsterdam: IOS Press, 1995:13-24.

10. Heathfield $H$, Wyatt J. The road to professionalism in medical informatics: a proposal for debate. Meth Inform Med 1995; 34: 426-33.

11. Kay S.Medical informatics at Manchester: Science and story. In: Hasman A, Albert A, WainwrightP, Klar R, Sosa M, eds.Education and Training in Health Informatics in Europe. Amsterdam: IOS Press, 1995:195207.

12. EDUCTRA Concerted Action 1992-1994. Advanced Informatics in Medicine, DGXIII Health Telematics.

13. Tierney WM, McDonald CJ. Testing informatics innovations: The value of negative trials. J Am Med Inform Assoc 1996; :358-9.

14. Collen MF. Origens of medical informatics. West J Med 1986;145:778-85.

15. Shortliffe EH, PerreaultLE, WiederholdG, Fagan LM. Medical Informatics, Computer Applications in Health Care. Reading, MA:
Addison-Wesley Publ Comp Inc, 1990.

16. EDUCTRA. Guidelines for European curricula.In: Hasman A, Albert A, Wainwright P, Klar R, Sosa M, eds. Education and Training in Health Informatics in Europe. Amsterdam: IOS Press,1995: 27-49.

17. Gremy F. Crisis of meaning and medical informatics education. Meth Inform Med 1989;28:189-95.

18. Stead WW. "JAMIA -Why?". J Am Med Inform Assoc 1994;1:75-6.

19. Protti DJ and Moehr JR. "Medical informatics and education: Progress, problems, and priorities" In: Van Bemmel JH, Zvarova J, eds. Knowledge, Information and MedicalEducation. Amsterdam: NorthHolland, 1991:3-10.

20. Blois MS, Shortliffe EH. The computer meets medicine: emergence of a discipline. In:Shortliffe EH, PerreaultLE, Wiederhold G, Fagan LM, eds. Medical Informatics, Computer Applications in Health Care. Reading, MA: Addison-Wesley PublComp Inc, 1990:19.

21. Winograd T, Flores F. Understanding Computers and Cognition. Norwood: Ablex Publishing, 1986:13.

22. HigherEducation Funding Council for England (HEFCE). Quality Assessment of Computer Science. http:/www.niss.ac.uk/ education/hefce/pub95/qo_8_95.html

23. Harel D.Algorithmics: The Spirit of Computing, $2^{\text {nd }}$ ed. Reading, MA: AddisonWesley Publ Comp, 1996.

24. Kay $S$. The enduring qualities of medical informatics. In: Chytil MK, Duru G, van Eimeren W, Flagle CD, eds. Proceedings of the Fifth International Conference on System Science in Health Care. Prague: Omnipress, 1992: 1451-4.

25. Coiera E. Medical informatics. Brit Med J 1995; 10:1381-7.

26. Kay S, Purves IN. Medical records and other stories: a narratological framework. Meth Inform Med 1996;35:72-87.

Address for correspondence:

Dr. Stephen Kay,

Director of Studies, BSc Medical

Informatics,

Department of Computer Science,

The University,

Oxford Road,

Manchester M13 9PL, UK

e-mail: skay@cs.man.ac.uk 